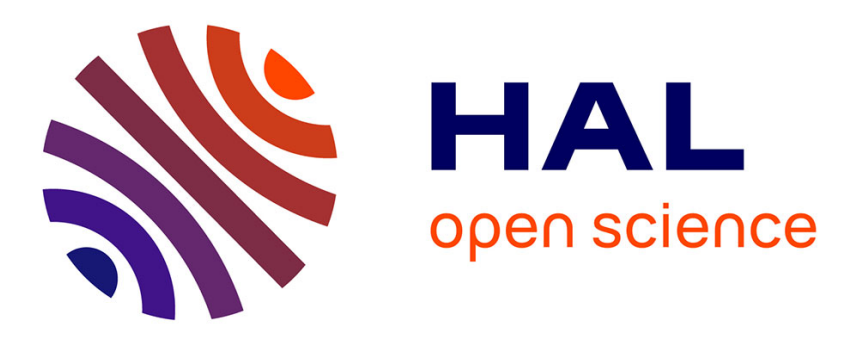

\title{
A New Approach to Analyze Chemical Releases Behavior in Water Column: High Speed Imaging
}

\author{
M. Fuhrer, Pierre Slangen, L. Aprin, G. Dusserre, S. Le Floch
}

\section{To cite this version:}

M. Fuhrer, Pierre Slangen, L. Aprin, G. Dusserre, S. Le Floch. A New Approach to Analyze Chemical Releases Behavior in Water Column: High Speed Imaging. International Oil Spill Conference Proceedings, 2011, 2011 (1), pp.abs168. 10.7901/2169-3358-2011-1-168 . hal-02299376

\section{HAL Id: hal-02299376 https://hal.science/hal-02299376}

Submitted on 8 Jun 2021

HAL is a multi-disciplinary open access archive for the deposit and dissemination of scientific research documents, whether they are published or not. The documents may come from teaching and research institutions in France or abroad, or from public or private research centers.
L'archive ouverte pluridisciplinaire HAL, est destinée au dépôt et à la diffusion de documents scientifiques de niveau recherche, publiés ou non, émanant des établissements d'enseignement et de recherche français ou étrangers, des laboratoires publics ou privés. 


\title{
A New Approach to Analyze Chemical Releases Behavior in Water Column:
} High Speed Imaging

\author{
M. Fuhrer [1,2], P. Slangen [2], L. Aprin [2], G. Dusserre [2], S. Le Floch [1]
}

[1] Cedre, Centre de Documentation, de Recherche et d'Expérimentations sur les pollutions accidentelles des eaux, 715, rue Alain Colas, CS 41836, F-29218 Brest Cedex 2, FRANCE, Melanie.Fuhrer@cedre.fr

[2] ISR, LGEI, Ecole des Mines d'Alès, 6, Avenue de Clavieres, F-30319 Ales Cedex FRANCE

\begin{abstract}
Shipping is the main method of chemical transportation and the volume is constantly increasing. Consequently, the risk of chemical accidents is also increasing. Among the latest accidents, many have led to vessels sinking.

The sinking of a chemical tanker induces a major risk of the release of the cargoes and or the release of the machine fuel oil. In both cases, the main question is: what will be the extent of the pollution at the sea surface? To answer this question, Cedre has developed an experimental device: the Cedre Experimental Column (CEC- $5 \mathrm{~m}$ high and $0.8 \mathrm{~m}$ in diameter). For floating products, experiments are designed to study their velocity during their transfer to the sea surface versus their dissolution kinetics.

This study is a joint project with Ecole des Mines d'Alès ensuring the development of optical techniques for onsite diagnostic of pollutants release (slow or sudden).

This paper deals with the dissolution rate of 15 chemical products selected, among others, in 3 families of organic compounds: alcohol, ketone and alkane. In each family the chosen products have an increasing number of carbon atoms which explains their very close physico-chemical parameters. Nevertheless, major discrepancies can be observed in their individual behavior. The chosen focus was on products with very different solubility limits: alkanes from oil are hydrophobic compounds, for ketone the solubilities range from $263 \mathrm{~g} / \mathrm{L}$ for 2-butanone (MEK) to $23 \mathrm{~g} / \mathrm{L}$ for cyclohexanone, and alcohols are soluble products.

Preliminary tests with MEK showed that the dissolution rate was low during its transfer in the CEC, despite its relatively high solubility. This result induces a risk of a slick formation at the sea surface. MEK's significant vapor pressure makes it an evaporating product and therefore forms a cloud when it has surfaced as a slick. This cloud is potentially explosive and thus represents a major danger for responders on site. These results highlight the limits of values gained from the literature and the need to perform experiments to better understand the behavior of chemicals at sea in order to provide more valuable information to authorities in charge of emergency response.
\end{abstract}




\section{Introduction}

The transport of chemicals by sea represents $11 \%$ of world trade. Today, chemical shipping is rapidly expanding and has multiplied by 3.5 in 20 years. Predictions foresee 175 million tones (Mt) of chemicals shipped by sea in 2011 and $181 \mathrm{Mt}$ in 2015 (Lacoste 2008).

Today, international regulations governing the transport of $\mathrm{HNS}^{1}$ are based on a theoretical assessment of their behavior (SEBC code ${ }^{2}$ - Bonn Agreement 1994) both to define which types of ships can transport a given substance (IBC code $^{3}$ - IMO 2007) and to assess the impact of these substances on the marine environment in the event of an accidental spill (MARPOL classification ${ }^{4}$ - IMO 2006). The release of a chemical at sea can have many, varied consequences. For instance, in water, the product may dissolve and contaminate marine flora and fauna; at the surface, the product may evaporate and form a toxic and/or explosive cloud.

The SEBC system classifies chemicals according to their theoretical behavior (dissolver, floater, evaporator, etc.) which is determined from their physico-chemical properties obtained in laboratory conditions according to standardized protocols. Solubilization, for instance, characterizes the saturated concentration of chemicals in fresh water at $20^{\circ} \mathrm{C}$ and at atmospheric pressure. These conditions are far from those encountered at sea in the event of a spill.

Therefore, while the SEBC code provides an initial indication of behavior, the operator in charge of response should take a critical approach to determine whether the specificities of the incident environment will alter the behavior and characteristics of the spilt chemical.

This problem was encountered during the accident of the chemical tanker Ievoli Sun (2000) in the English Channel, whereby the wreck lay $70 \mathrm{~m}$ deep with its cargo of styrene. This products solubility in seawater has proved to be half that of its freshwater solubility, resulting in an upwelling of styrene above the wreck. This causes safety problems for ships in the area as this product evaporates rapidly and forms a neurotoxic cloud. Knowing an increase in salinity in the aqueous phase generally leads to a decrease in the solubility of chemical substances (Xie, Shiu et al. 1997), this process is nevertheless not quantified, and only theoretical equations far from field realities are available.

Moreover, the difference in density between the seawater and the product spilt directly influences the speed at which the chemical rises to the surface and, consequently, its dissolution. The example of the incident involving the chemical tanker Ece illustrates this point. In 2006, the Ece sank in waters $70 \mathrm{~m}$ deep with 10,000 tones of phosphoric acid onboard. This acid is classed as a dissolver by the SEBC classification, however trials conducted by Cedre showed that its relative density (1.58 higher than seawater) led to the stagnation of the acid on the seafloor and therefore, without agitation, the acid has a lower solubility (Cedre 2006).

Hence, in the case of a wreck, the quantity of phosphoric acid liable to rise through the water column to form a surface slick, and therefore present a danger for onsite responders, cannot currently be accurately assessed.

This paper presents preliminary tests conducted to characterize the upward movement of 15 chemicals in a column of seawater. The aim of these initial tests was to define the main characteristics influencing the speed at which the chemicals rose to the surface, as well as

\footnotetext{
${ }^{1}$ Hazardous and Noxious Substances

2 SEBC: Standard European Behaviour Classification system of chemicals spilled into the sea.

3 IBC Code: International Bulk Chemical Code

${ }^{4}$ MARPOL: International Convention for the Prevention of Pollution from Ships.
} 
their dissolution rate, in order to produce a computerized predictive model to assist operators in charge of response.

\section{Materials and methods}

The aim of this experimental investigation is to characterize liquid chemicals with a density lower than seawater. It is designed to observe the speed at which the chemicals rise and dissolve.

\subsection{Experimental set-up}

The experimental apparatus is composed of the Cedre Experimental Column (CEC) equipped with an injection system and a high speed video recording system.

The CEC is a five meter high hexagonal column with a diameter of $0.8 \mathrm{~m}$ and a total capacity of 2,770 L (Figure 1). The water in the column is static. Four walls are made of glass, allowing observation and video recording within the column. A technical description of the CEC is also provided in (Le Floch, Benbouzid et al. 2009).

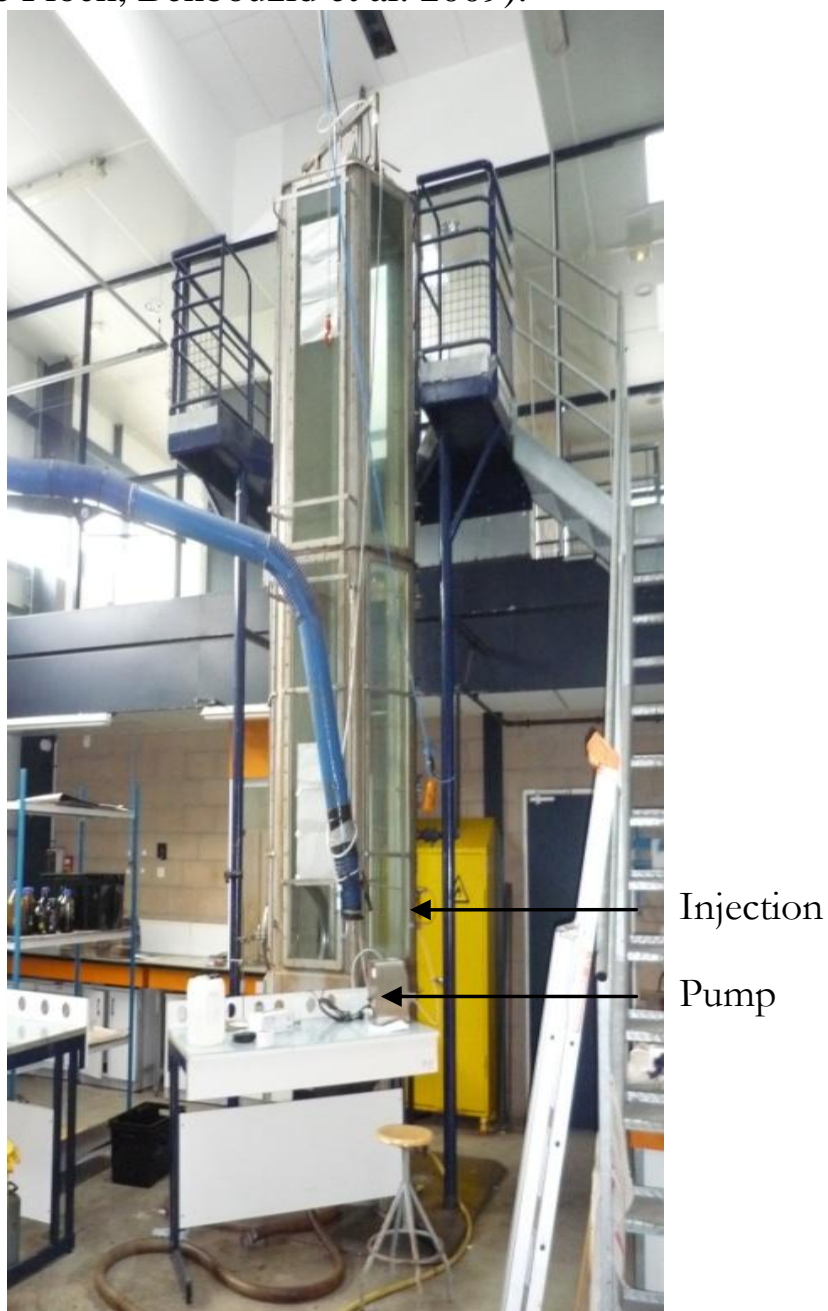

Figure 1: The Cedre Experimental Column

A gear pump equipped with a pump head ensures the injection of the chemicals at a regular, defined rate (50 to $300 \mathrm{~mL} \cdot \mathrm{min}^{-1}$ ). A $40 \mathrm{~cm}$ long injection tube combined with a 2 mm diameter nozzle channeled the chemicals into the centre of the column.

As most of the products are transparent in seawater, a light diffuser set-up enabled the droplets to be visualized. The high speed camera records at 200 image. $^{-1}$ with a resolution of 
$640 \times 480$ pixels. The area of interest (centre of the column) represents $23 \times 30 \mathrm{~cm}$, that is $390 \times 470$ pixels, corresponding to a pixel resolution of approximately $0.6 \mathrm{~mm}$.

Table 1: Equipment references

\begin{tabular}{|c|c|c|c|}
\hline Gear pump & $\begin{array}{l}\text { ISMATEC-IP } 65 \\
\text { MCP-Z process }\end{array}$ & $\begin{array}{l}\text { Labortechnik- } \\
\text { Analytik }\end{array}$ & Glattburgg-Zürich \\
\hline Pump head & Micropump GA-T23 & $\begin{array}{l}\text { Labortechnik- } \\
\text { Analytik }\end{array}$ & Glattburgg-Zürich \\
\hline Camera & PIKE F-032B & $\begin{array}{c}\text { Allied Vision } \\
\text { Technologies GmbH }\end{array}$ & Stadtroda / Germany \\
\hline
\end{tabular}

\subsection{Test Products}

\section{Chemical substances}

The studied substances are liquid with a density lower than seawater. They have been selected according to their frequency of transportation, accidents involving these chemicals and their hazardous nature. These substances are chosen to cover a wide range of physicochemical properties, while categorizing them in order to associate a category of chemicals with a standard behavior. The physico-chemical properties used to select products are:

- hydrosolubility and vapor pressure, combined with density, are used to theoretically determine behavior for the SEBC classification

- kinematic viscosity and surface tension, as they appear in fluid dynamics equations.

The alkanes, alcohols and ketones are the chosen families. To validate the link between category and standard behavior, products from the same chemical families were added (2-pentanone, 2-hexanone and pentane). Organic compounds, belonging to these families and others, represent $50 \%$ of chemical shipping by sea and comes from petrochemistry (Lacoste 2008).

In addition, a group of chemicals classified as "Miscellaneous" are also studied due to their high volume of shipping and their involvement in past accidents, (Styrene and vinyl acetate). Di(2-ethylhexyl)phthalate (DEHP) and Methyl-tert-butyl ether (MTBE) were tested not only due to their high level of shipping but also respectively for their high viscosity or low hydrosolubility and high vapor pressure.

Table 2 presents the products tested along with their physico-chemical properties.

\section{Seawater}

The seawater used to fill the column is taken from the bay of Brest. Before being used it is filtered to remove particles over $25 \mu \mathrm{m}$ in suspension, and is treated with UV $\left(25 \mathrm{~mJ} . \mathrm{cm}^{-}\right.$ ${ }^{2}$ ) rays. These treatments prevent flocculation between the substances injected and the matter in suspension so as not to interfere with dissolution kinetics. This seawater has a salinity of $27 \mathrm{~kg} \mathrm{~m}^{-3}$ and the temperature during the tests is $18^{\circ} \mathrm{C}$. The refractive index of the seawater is 1.34 (Copin-Montégut 2002).

\subsection{Protocol for each chemical}

The experimental protocol consists of injecting the substance at the bottom of the column and monitoring the flow, using image recordings at two distinct heights. All tests are performed with an injection rate varying between 50 and $300 \mathrm{~kg} / \mathrm{m}^{3}$. During the test the injection rate is fixed to obtain a permanent trail of drops and to enable their analysis. The video recording begins when the first drops are injected. 
The optical set-up is then moved to the top of the column and the same operations are carried out.

Images at the bottom of the column are recorded a few centimeters above the injection nozzle (injection - bottom of image $=7 \mathrm{~cm}$ ). The distance between the injection point and the centre of the images recorded at the top of the column is $301 \mathrm{~cm}$. 
Table 2: Characteristics of chemicals studied

\begin{tabular}{|c|c|c|c|c|c|c|c|}
\hline Family & Name & $\begin{array}{c}\text { CAS } \\
\text { number }\end{array}$ & $\begin{array}{l}\text { Molar mass } \\
\qquad \mathrm{g} \mathrm{mol}^{-1}\end{array}$ & $\begin{array}{c}\text { Density at } 20^{\circ} \mathrm{C} \\
\left(\text { water at } 4^{\circ} \mathrm{C} \text { ) }\right.\end{array}$ & $\begin{array}{c}\text { Hydrosolubility } \\
\text { at } 20^{\circ} \mathbf{C} \\
\mathrm{g} \mathrm{L}^{-1}\end{array}$ & $\begin{array}{c}\text { Kinematic viscosity } \\
\text { at } 20^{\circ} \mathbf{C} \\
10^{-6} \mathrm{~m}^{2} \mathrm{~s}^{-1}\end{array}$ & $\begin{array}{c}\text { Refractive index } \\
\text { Sodium D line } \\
\text { at } 20^{\circ} \mathrm{C}\end{array}$ \\
\hline \multirow{3}{*}{ Alcohol } & Ethanol & $64-17-5$ & 46.07 & 0.79 & 790 & 1.51 & 1.36 \\
\hline & 2-Propanol & $67-63-0$ & 60.09 & 0.79 & 790 & 3.05 & 1.38 \\
\hline & 1-Butanol & $71-36-3$ & 74.12 & 0.81 & 77 & 3.7 & 1.40 \\
\hline \multirow{5}{*}{ Ketone } & Acetone & $67-64-1$ & 58.08 & 0.79 & 790 & 0.4 & 1.36 \\
\hline & $\mathrm{MEK}^{5}$ & $78-93-3$ & 72.11 & 0.81 & 263 & 0.51 & 1.38 \\
\hline & 2-Pentanone & $107-87-9$ & 86.13 & 0.81 & $59.5 .10^{-3}$ & 0.61 & 1.39 \\
\hline & 2-Hexanone & $591-78-6$ & 100.16 & 0.81 & $17.5 .10^{-3}$ & 0.76 & 1.40 \\
\hline & Cyclohexanone & $108-94-1$ & 98.15 & 0.95 & 23 & $2.32\left(25^{\circ} \mathrm{C}\right)$ & 1.45 \\
\hline \multirow{3}{*}{ Alkane } & Pentane & $109-66-0$ & 72.15 & 0.63 & $38.10^{-3}\left(25^{\circ} \mathrm{C}\right)$ & 0.37 & 1.36 \\
\hline & Hexane & $110-54-3$ & 86.18 & 0.66 & $9.5 .10^{-3}$ & 0.47 & 1.37 \\
\hline & Heptane & $142-82-5$ & 100.2 & 0.68 & $3.4 .10^{-3}\left(25^{\circ} \mathrm{C}\right)$ & 0.6 & 1.39 \\
\hline \multirow{4}{*}{ Miscellaneous } & Vinyl acetate & $108-05-4$ & 86.09 & 0.93 & 20 & 0.46 & 1.40 \\
\hline & $\mathrm{DEHP}^{6}$ & $117-81-7$ & 390.6 & 0.98 & $3.10^{-6}$ & 82.4 & 1.49 \\
\hline & $\mathrm{MTBE}^{7}$ & $1634-04-4$ & 88.15 & 0.74 & 48 & 0.47 & 1.37 \\
\hline & Styrene & $100-42-5$ & 104.15 & 0.91 & 0.3 & 0.83 & 1.55 \\
\hline
\end{tabular}

${ }^{5}$ MEK: Methyl Ethyl Ketone (2-Butanone)
${ }^{6}$ DEHP: Di(2-ethylhexyl)phthalate

7 MTBE: Methyl-tert-butyl ether 


\section{Results and discussion}

\subsection{Dissolution}

The highly soluble products (Solubility $\mathrm{S}=790,000 \mathrm{mg} . \mathrm{L}^{-1}$ i.e. ethanol, propanol and acetone) dissolved almost instantaneously. These products generate an easily visible plume (Figure 2).

MEK (S = $263000 \mathrm{mg} . \mathrm{L}^{-1}$, Figure 3) and butanol $\left(\mathrm{S}=77000 \mathrm{mg} \cdot \mathrm{L}^{-1}\right.$, Figure 4a) almost entirely dissolved throughout the column. During the time to reach the top of the column, only small droplets of MEK could be seen (1 pixel $=0.5 \mathrm{~mm}$ ), while the butanol forms droplets of around $2 \mathrm{~mm}$ in diameter (Figure $4 b$ ).

These solubilization kinetics should be compared with the tested rates (100 to $175 \mathrm{~mL} \cdot \mathrm{min}^{-1}$ ). Indeed, MEK was tested by Cedre following the Ievoli Sun incident. These previous tests showed that, for high release rates (complete, instantaneous release of $1 \mathrm{~L}$ of MEK at the bottom of the column), the rate at which the chemical rose was too high to allow total dissolution of the product and almost all of the chemical could be recovered at the top of the column (Poisson 2001).

The current rate is therefore low enough to allow almost complete dilution over a relatively short distance, but too high to form a trail of distinct drops. A plume of droplets is then observed at the bottom of the column (Figure 3 and Figure 4a).

\subsection{Trails of drops}

The alkanes (pentane, hexane, heptane - Figure 5 to Figure 7) and certain "miscellaneous" substances (vinyl acetate - Figure 8, DEHP - Figure 9 and styrene - Figure 10) formed trails of drops, spaced out to varying degrees, following a tight spiral trajectory. Figure 9 shows the trajectory of DEHP drops.

These trails of chemicals formed groups of drops while rising. These groups of drops showed the differences in speed between the drops of the same group. The closer the drops were together, the greater the differences in velocity and the quicker the grouping of drops. The differences in speed can be explained by the interaction between drops. Many studies (Rabha and Buwa 2010) illustrate the influence of the volume fraction of different phases on the velocity at which drops rise and on the drag coefficient (drag force is dominant in this study). A depression forms in the wake of a drop, increasing the speed of lower drops.

This effect can be seen for the different rates of DEHP or styrene tested. At slow rates (less than $150 \mathrm{~mL} \cdot \mathrm{min}^{-1}$ ), the drops spacing became closer but drops did not group together: the distance between drops is large enough to avoid drops interaction, they have no "time" to group together (Figure 9, Figure 10). For high rates (greater than $200 \mathrm{~mL} \cdot \mathrm{min}^{-1}$ - Figure 11, Figure 12) the drops are gathered together at the top of the column. Figure 18 shows images originally from a record allowing to follow the inversion of 3 drops of DEHP over a distance of $10 \mathrm{~cm}$, i.e. the third and last drop formed rise more quickly than the first and "overtake" it. For vinyl acetate, a rate of $120 \mathrm{~mL} \cdot \mathrm{min}^{-1}$ is sufficient to show the differences in velocity (Figure 13).

\subsection{Droplet plumes}

The ketones (2-pentanone - Figure 14; 2-hexanone - Figure 15; cyclohexanone - Figure 16) as well as MTBE (Figure 17) also present a droplet plume.

The different records of these plumes show the difference in the velocity at which the drops rise between the inside and outside of the plume. These differences can also be explained by the influence of volume fractions on the drag force. 


\subsection{Viscous products}

The most viscous products (butanol - Figure 4, cyclohexanone - Figure 16, DEHP) formed a neck between being injected and forming a drop for high rates (Zhang 1999; Cramer, Fischer et al. 2004). This neck reaches over $10 \mathrm{~cm}$ for DEHP (Figure 19) and appears for rates higher than $150 \mathrm{~mL} \cdot \mathrm{min}^{-1}$. Furthermore, the stretching and constriction of the neck leads to the formation of satellite droplets during the formation of primary drops (Figure 19). These droplets formed from 180 $\mathrm{mL} \cdot \mathrm{min}^{-1}$ for DEHP. These two chemicals therefore have 2 classes of drop sizes: primary drops, 10 to $15 \mathrm{~mm}$ in diameter, and satellite drops, between 1 and $2 \mathrm{~mm}$ (values taken for DEHP - Figure 11 and Figure 18). 


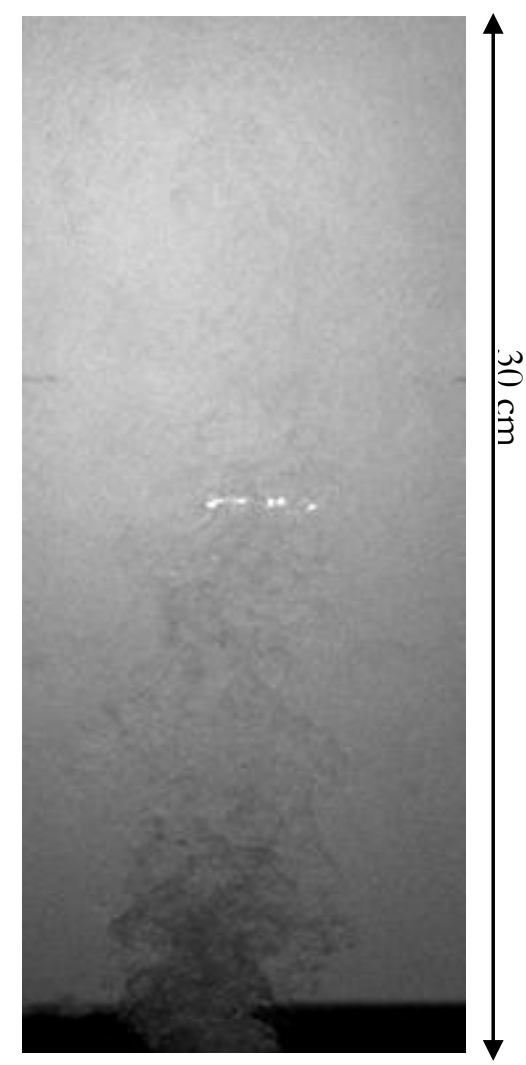

Figure 2: Dilution plume of propanol (rate: 250 mL.min ${ }^{-1}$ )

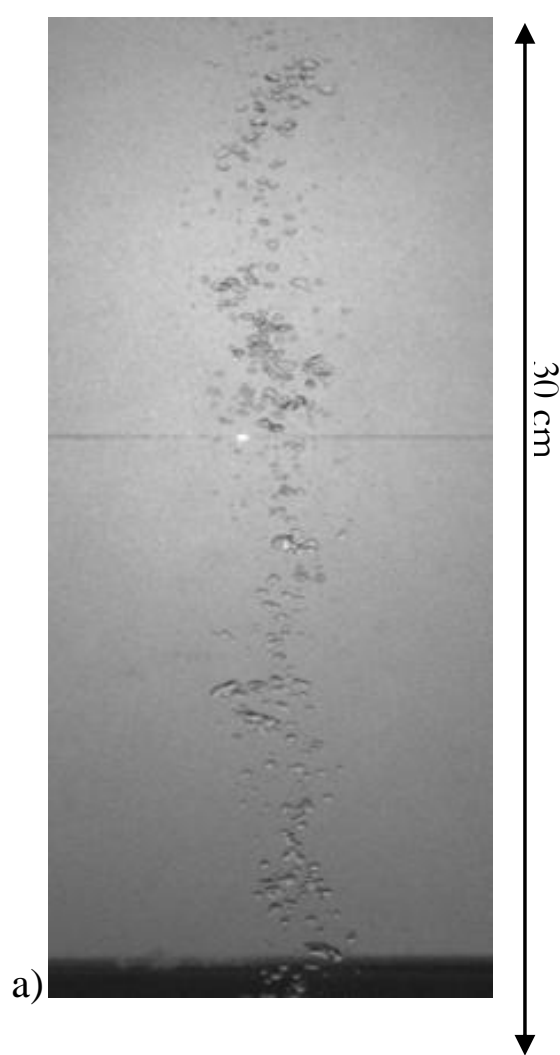

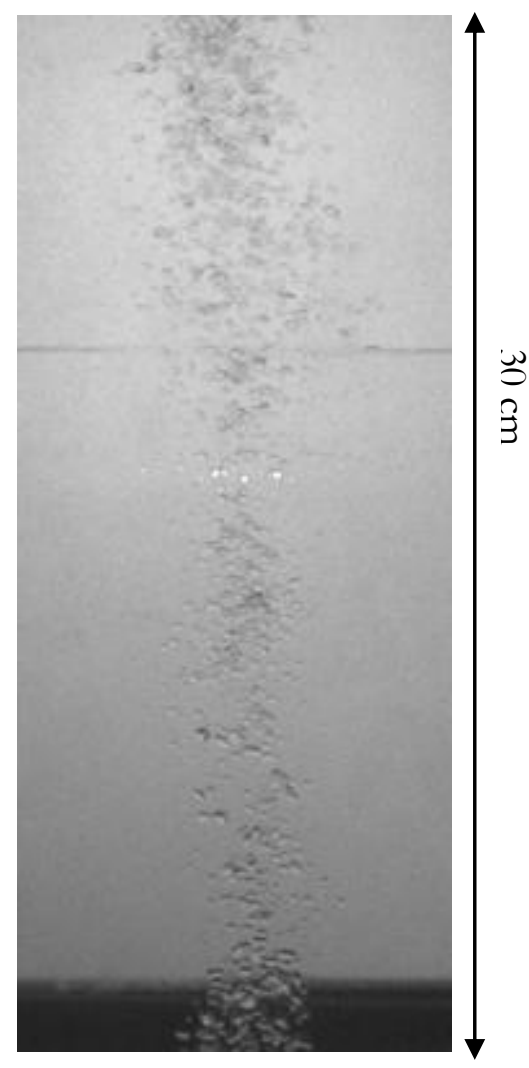

Figure 3: Droplet plume of MEK (rate: $150 \mathrm{~mL} \cdot \mathrm{min}^{-1}$ )

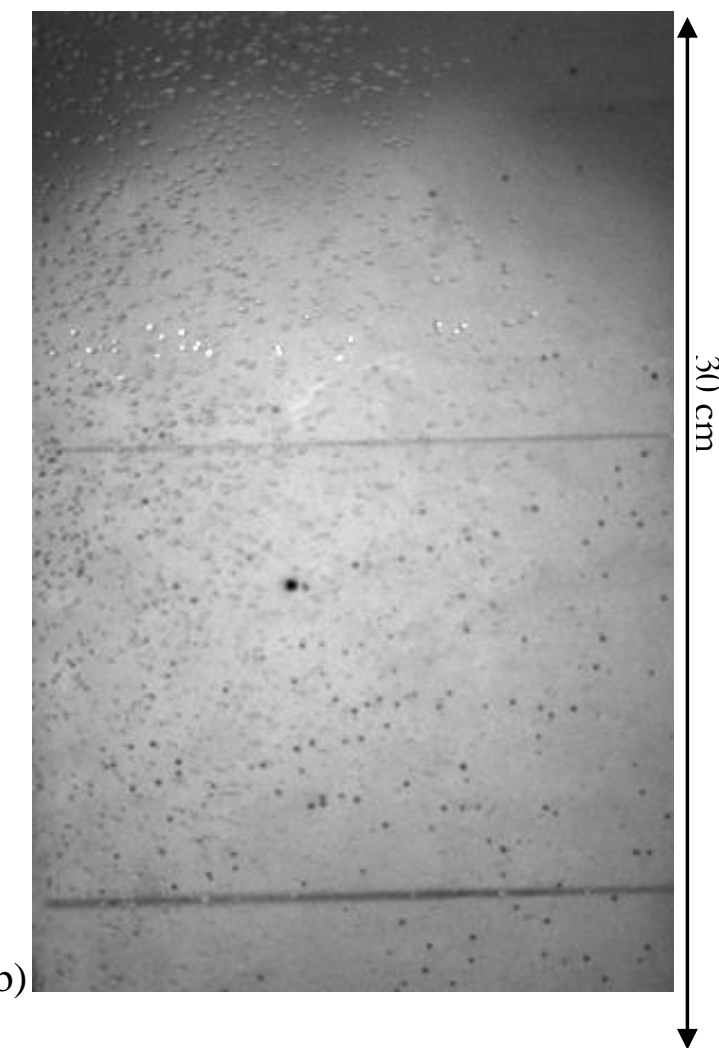

Figure 4: Droplet plume of butanol a) at the bottom b) at the top of the column 
(rate: 150 mL.min ${ }^{-1}$ ) 

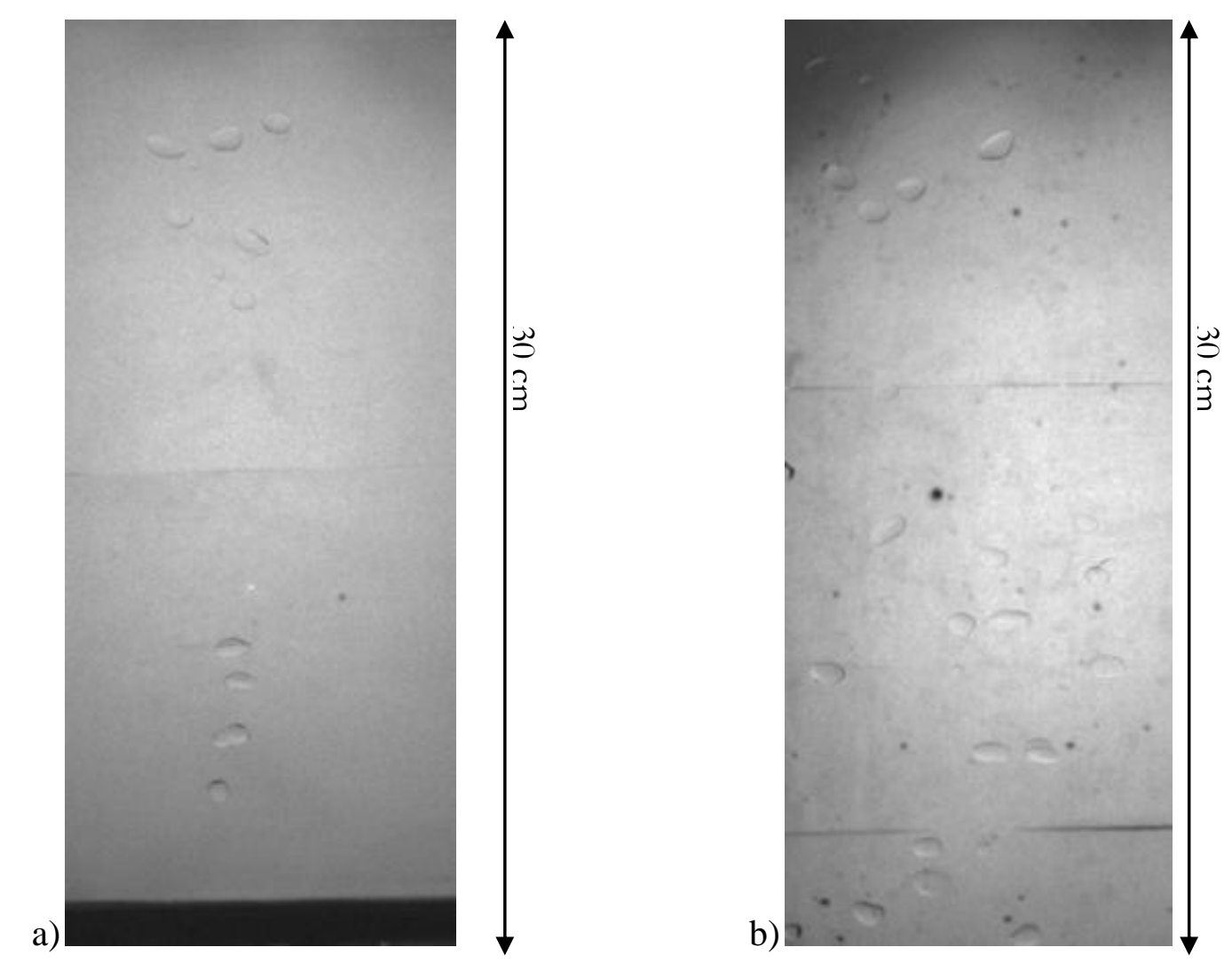

Figure 5: Drops of pentane a) at the bottom b) at the top of the column (rate: $140 \mathrm{~mL} \cdot \mathrm{min}^{-1}$ )
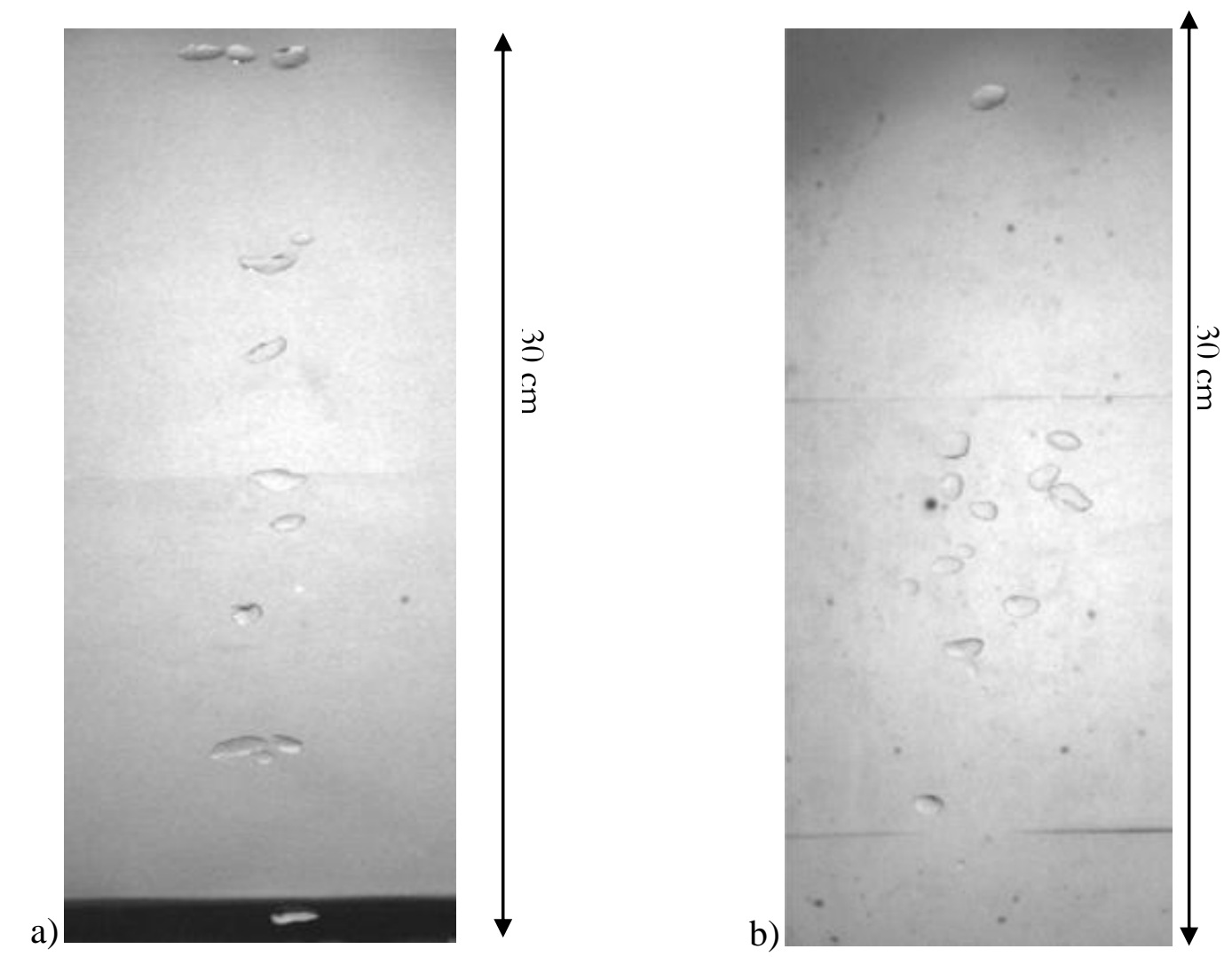

Figure 6: Drops of hexane a) at the bottom b) at the top of the column (rate: $130 \mathrm{~mL} \cdot \mathrm{min}^{-1}$ ) 

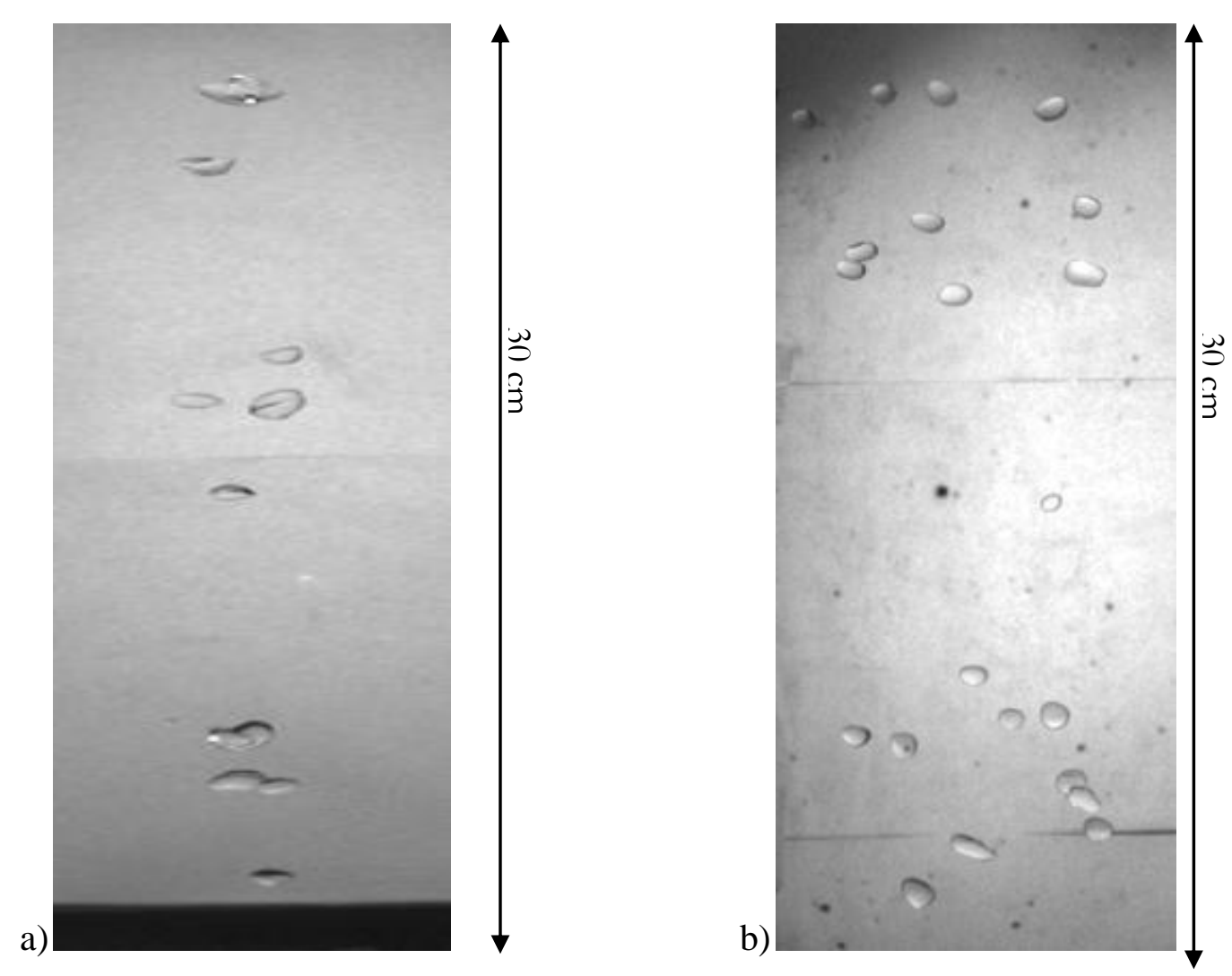

Figure 7: Drops of heptane a) at the bottom b) at the top of the column (rate: $130 \mathrm{~mL} . \mathrm{min}^{-1}$ )
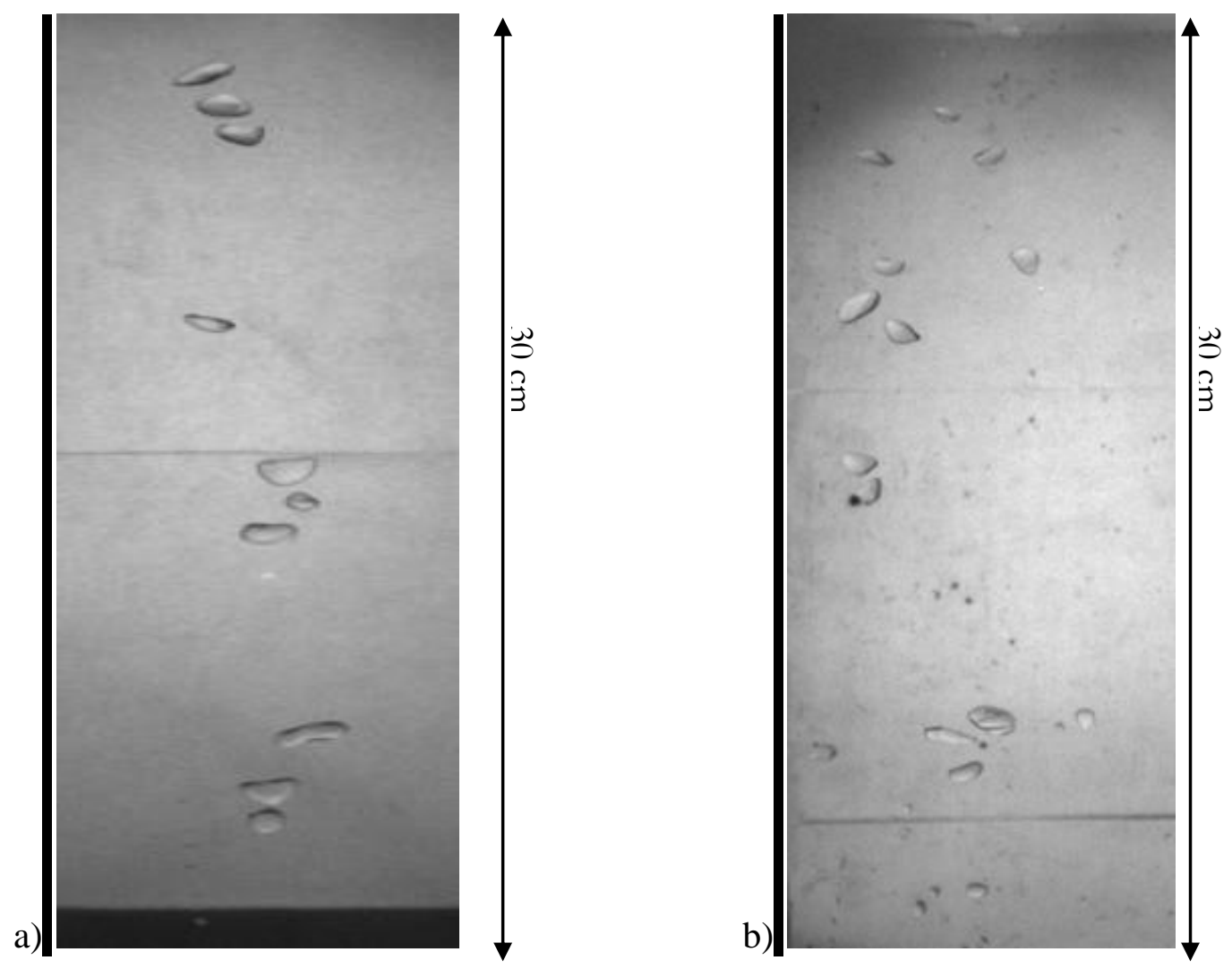

Figure 8: Drops of vinyl acetate a) at the bottom b) at the top of the column (rate: 130 mL. $\mathrm{min}^{-1}$ ) 

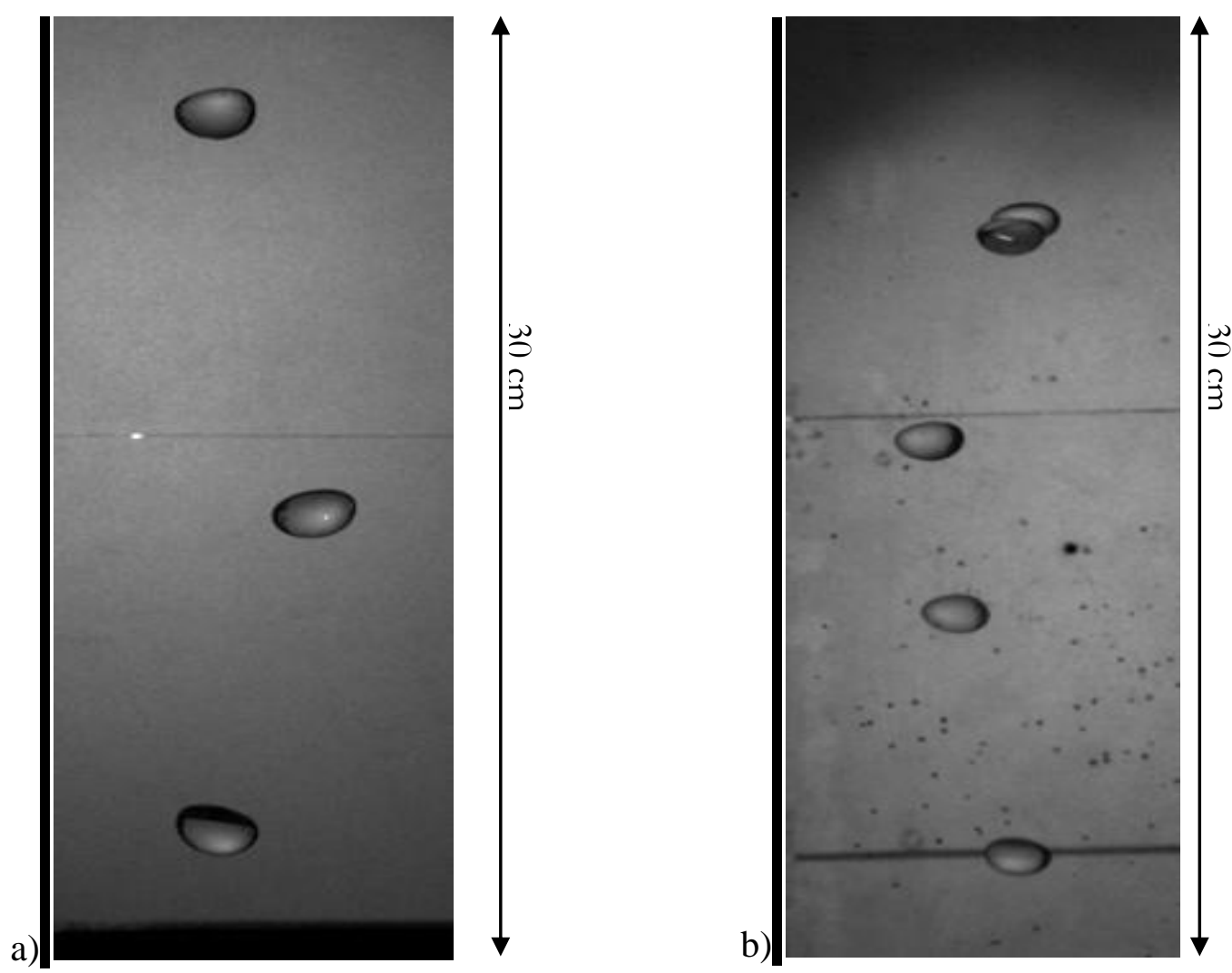

Figure 9: Drops of DEHP a) at the bottom b) at the top of the column (rate: 120 mL.min ${ }^{-1}$ )
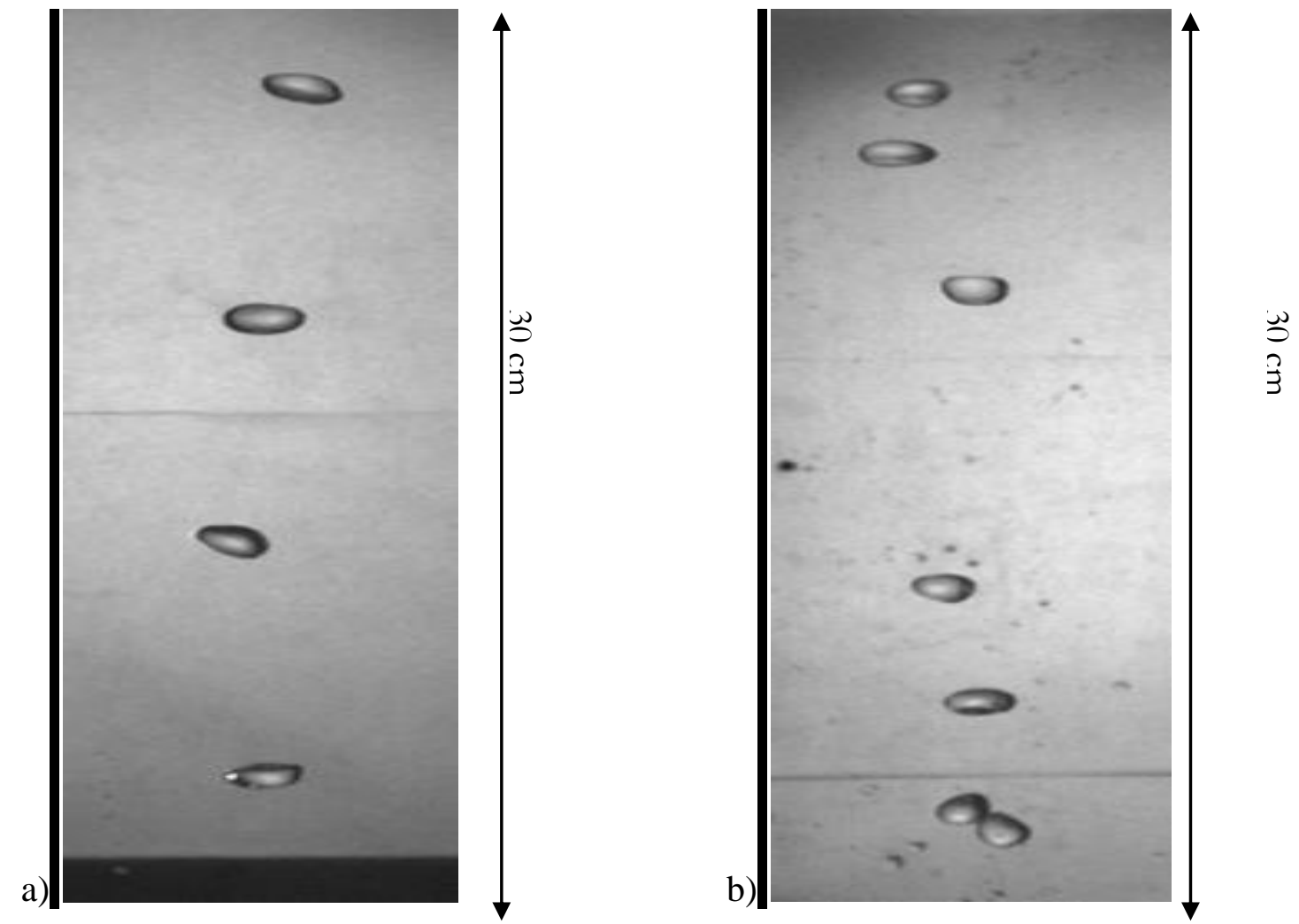

Figure 10: Drops of styrene a) at the bottom b) at the top of the column (rate: 130 mL.min ${ }^{-1}$ ) 

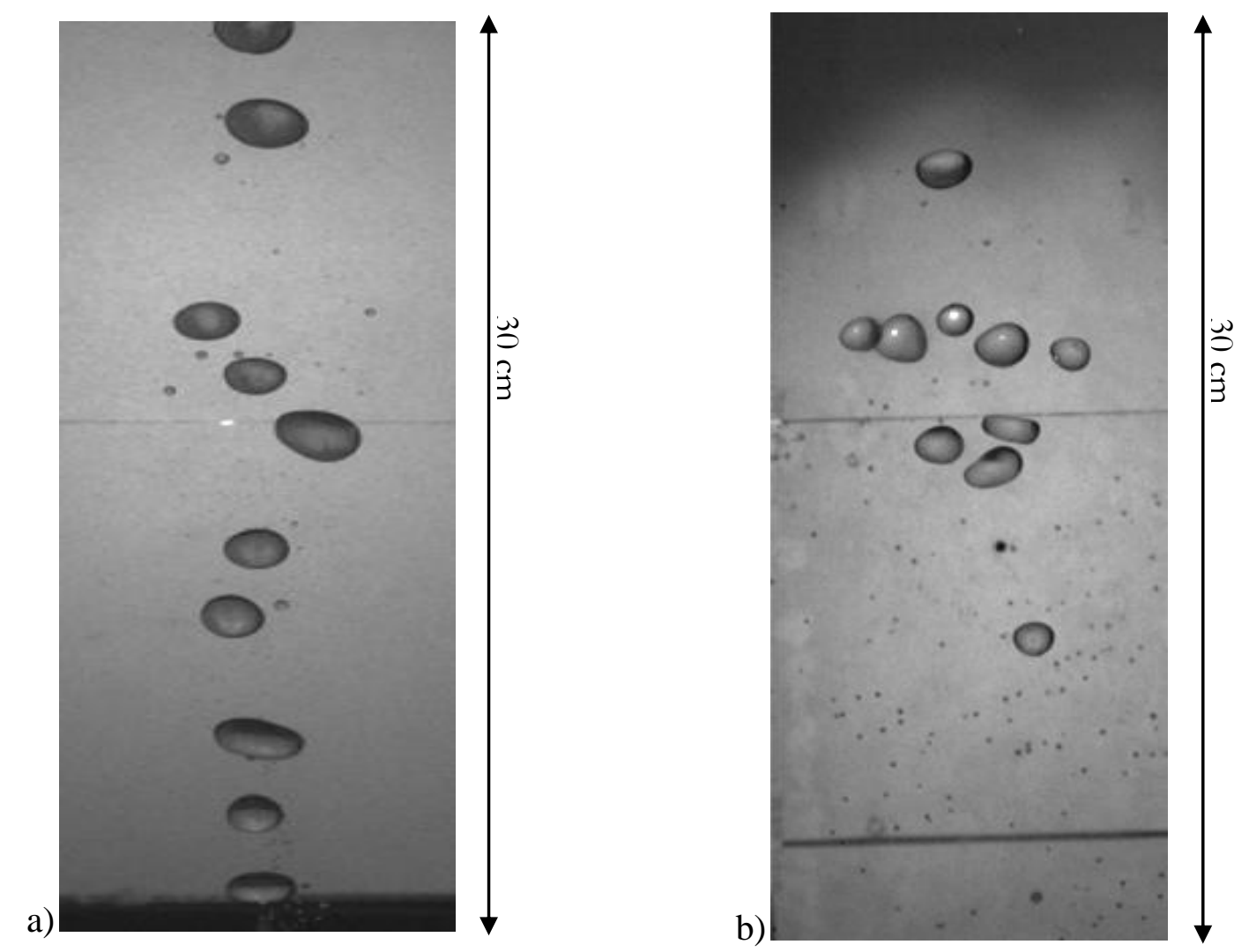

Figure 11: Drops of DEHP a) at the bottom b) at the top of the column (rate: 360 mL.min ${ }^{-1}$ )
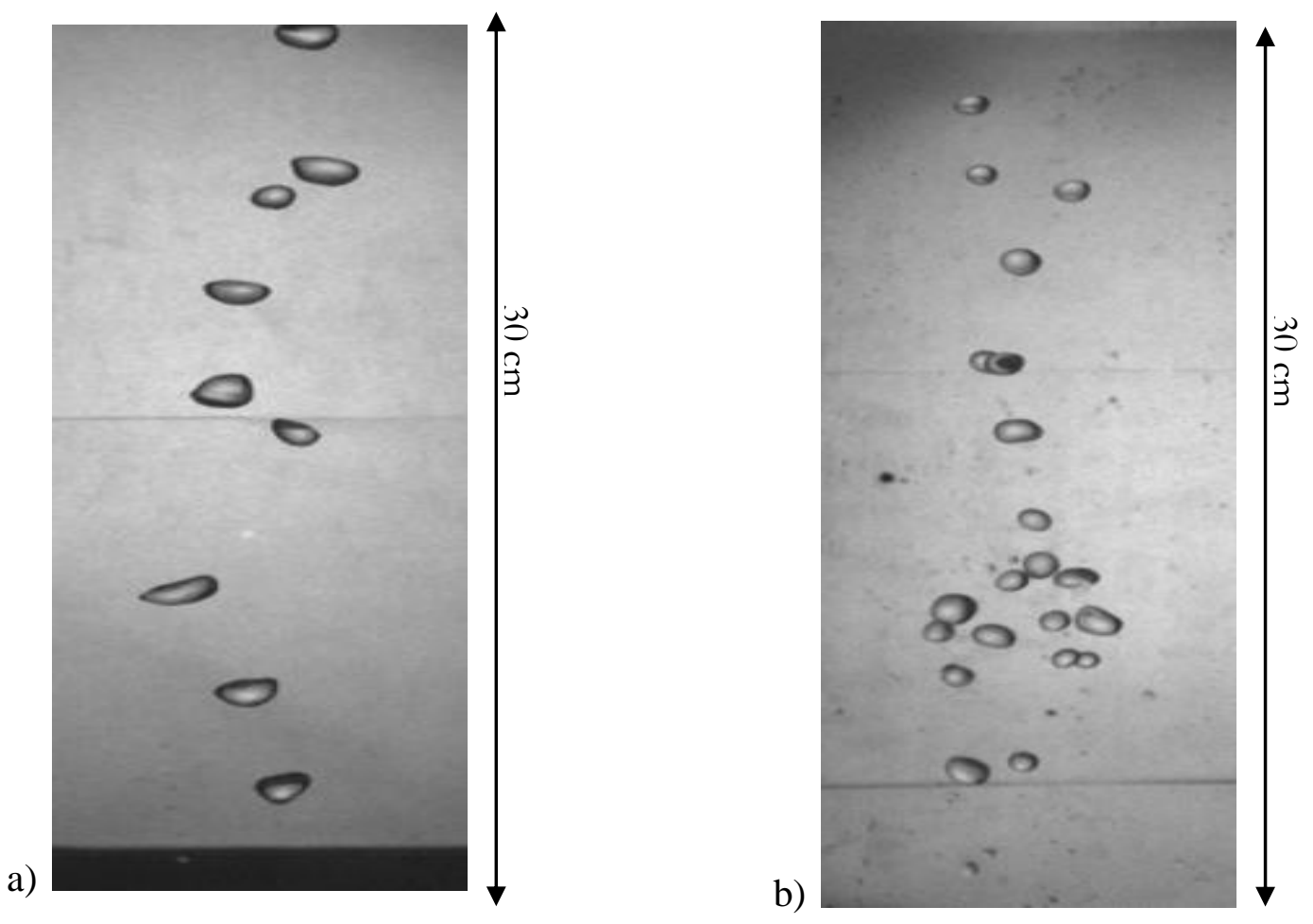

Figure 12: Drops of styrene a) at the bottom b) at the top of the column (rate: 210 mL.min ${ }^{-1}$ ) 


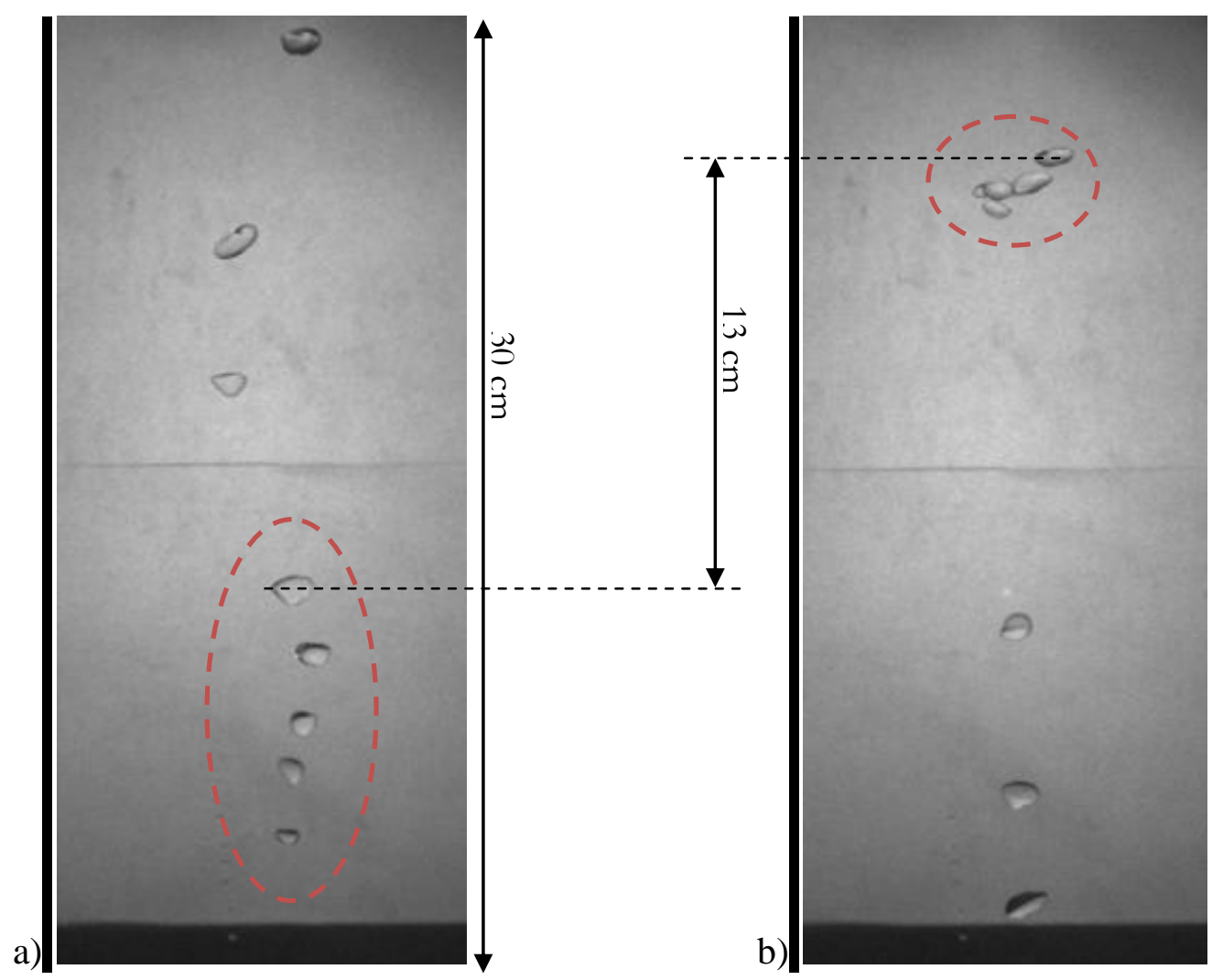

Figure 13: Evolution of the trail of drops of vinyl acetate (rate: $120 \mathrm{~mL} \cdot \mathrm{min}-1, \quad=1.3 \mathrm{~s}$ )

a)

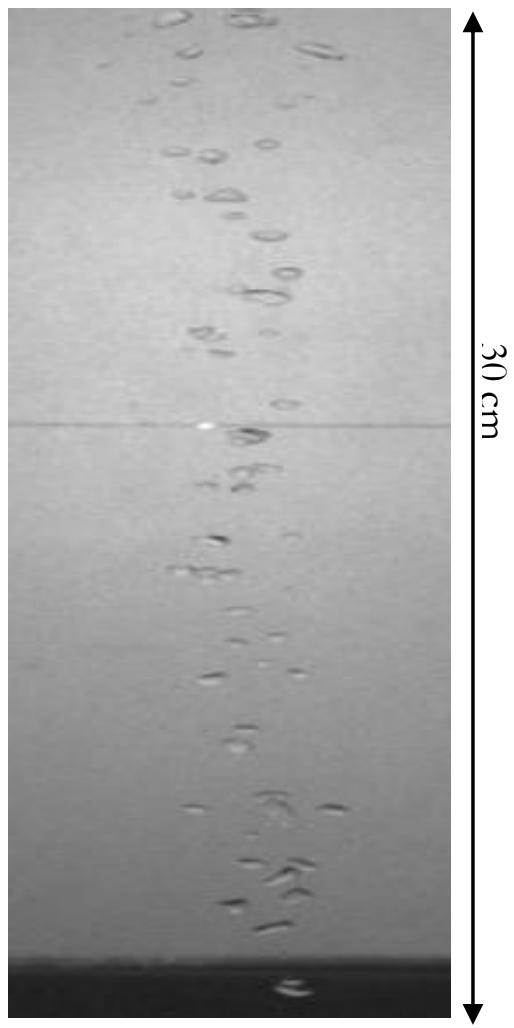

b)

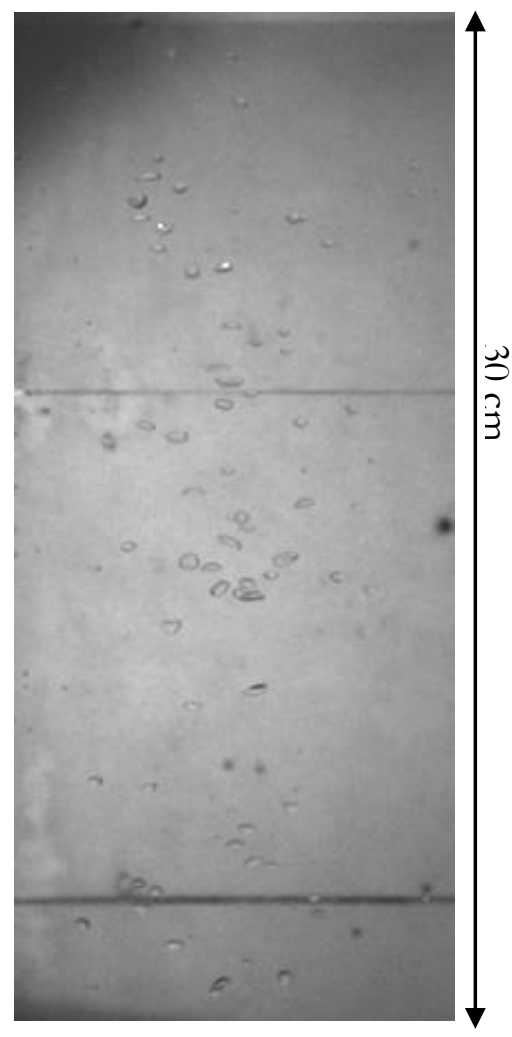

Figure 14: Droplet plume of 2-pentanone a) at the bottom b) at the top of the column (rate: $140 \mathrm{~mL} \cdot \mathrm{min}^{-1}$ ) 

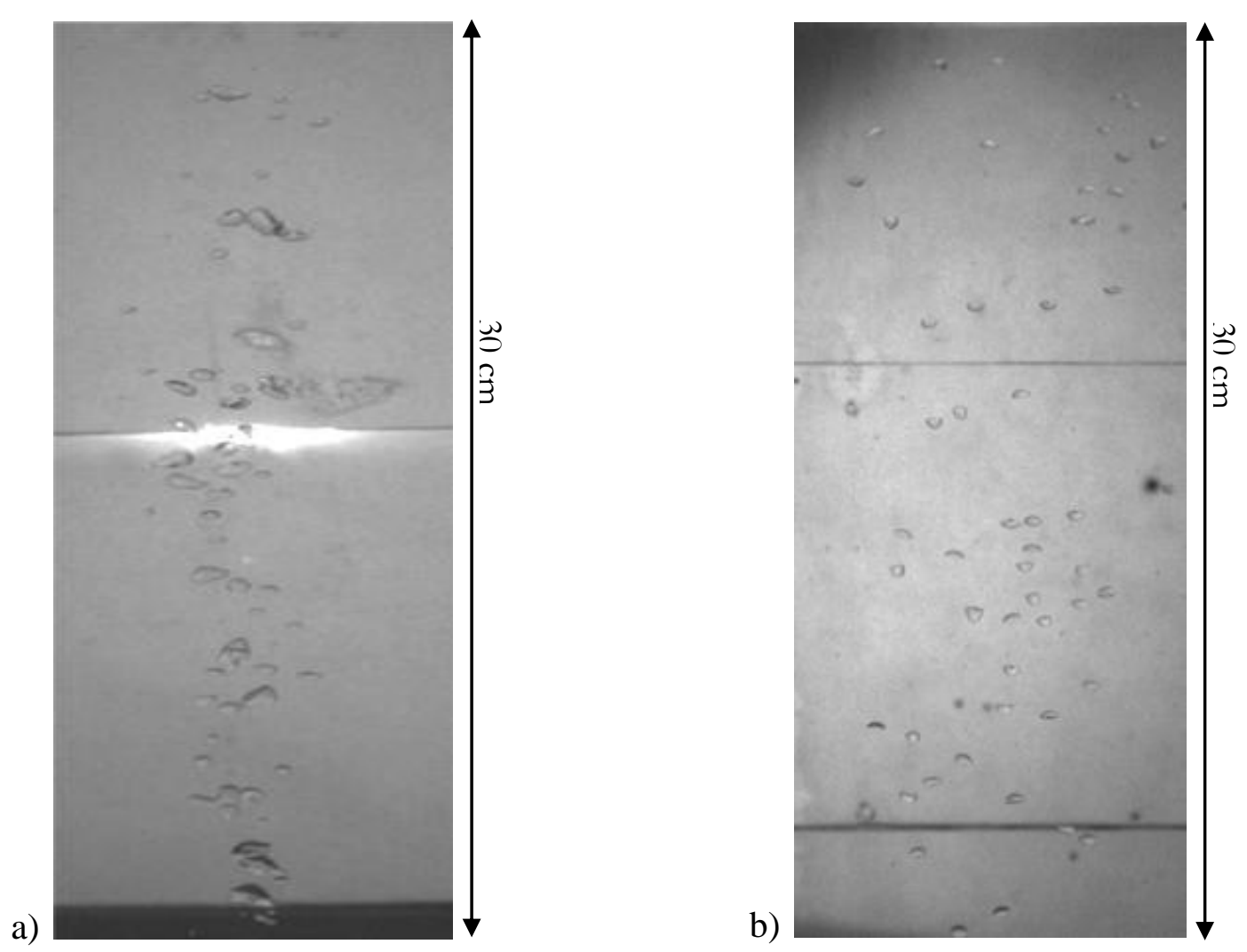

Figure 15: Droplet plume of 2- hexanone a) at the bottom b) at the top of the column (rate: 130 mL.min ${ }^{-1}$ )
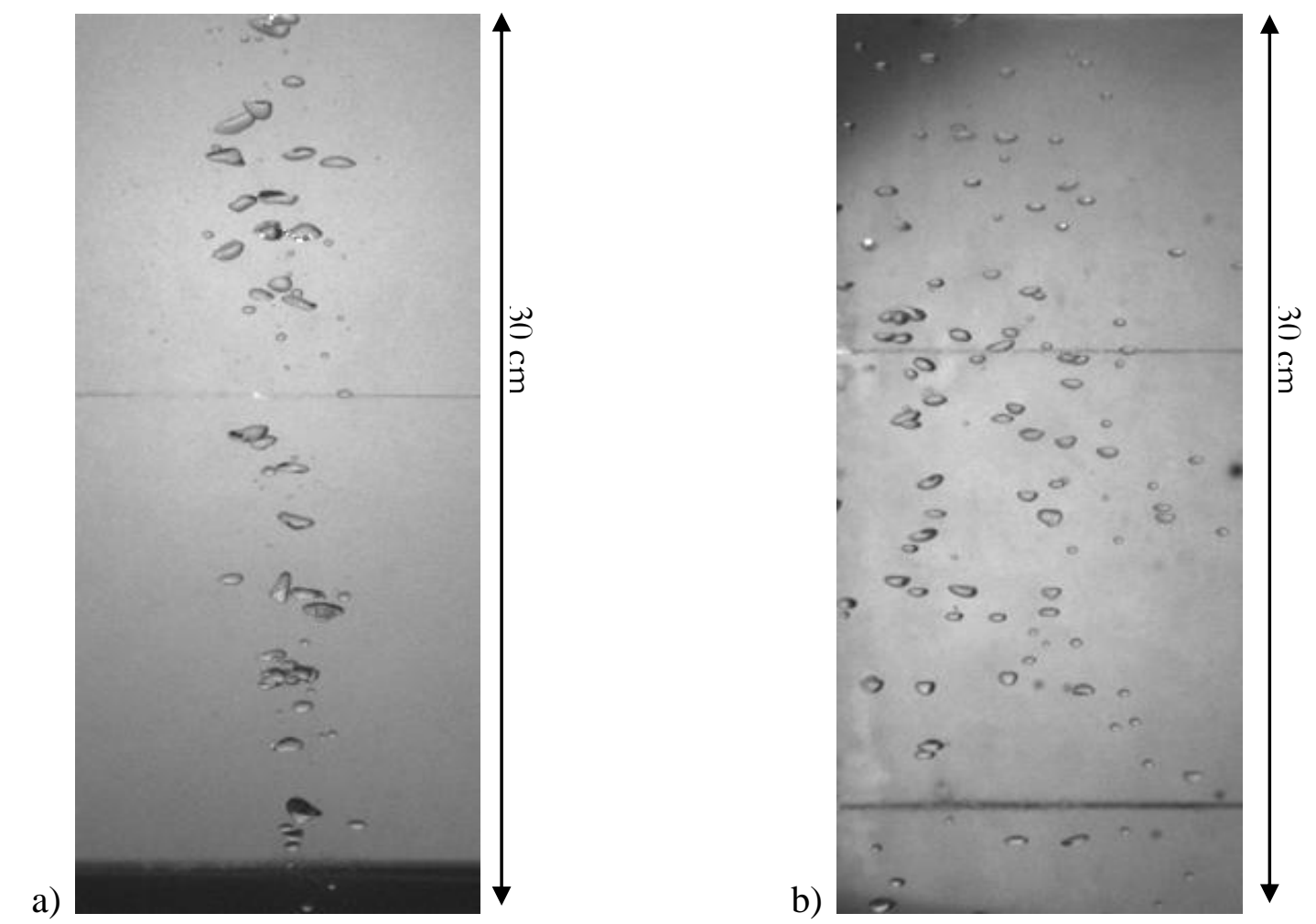

Figure 16: Droplet plume of cyclohexanone a) at the bottom b) at the top of the 


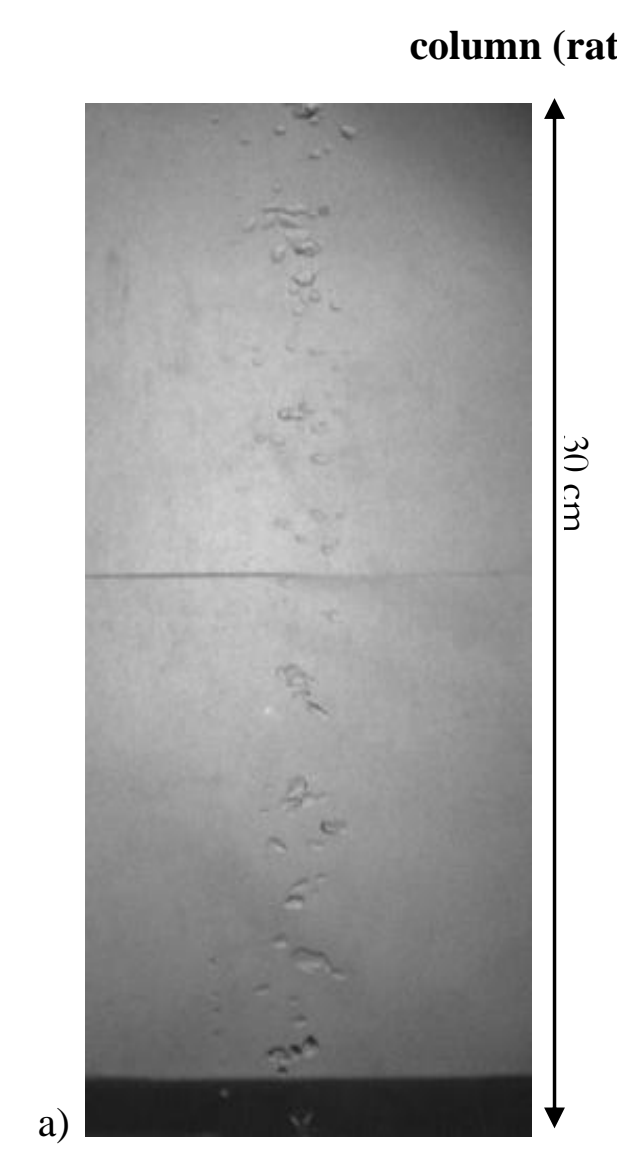

b)

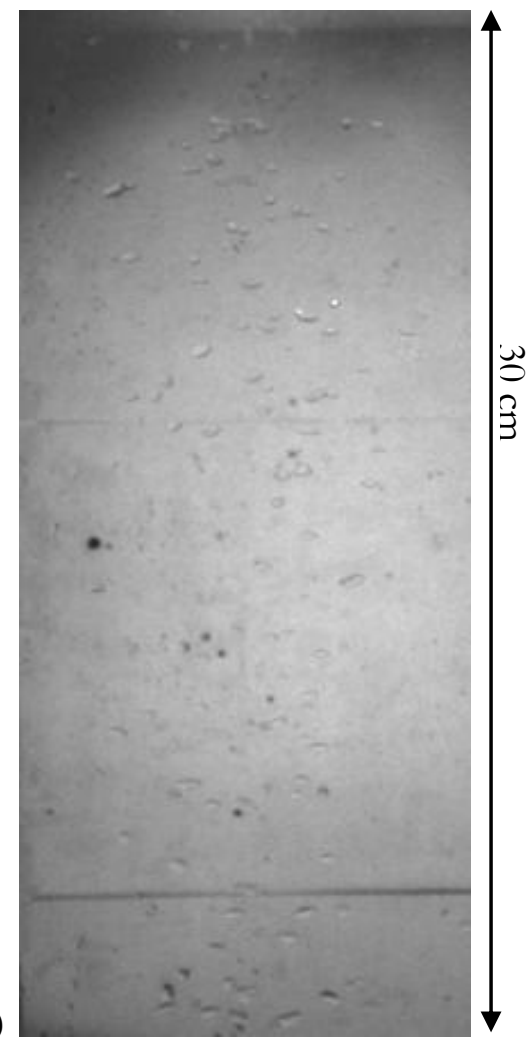

Figure 17: Droplet plume of MTBE a) at the bottom b) at the top of the column (rate: 130 mL.min ${ }^{-1}$ ) 

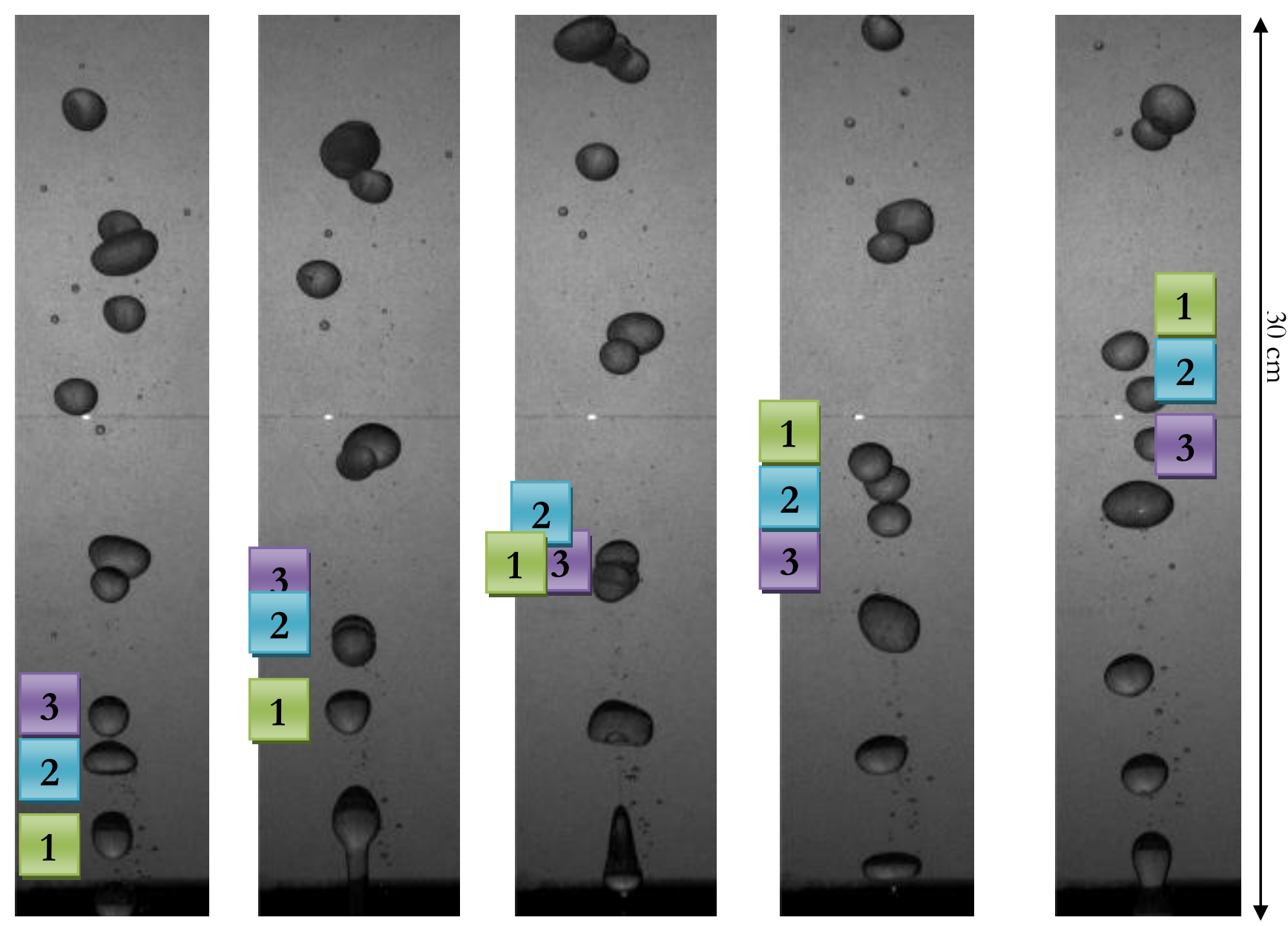

Figure 18: Difference in speed between three drops of DEHP (labelled 1, 2 and 3 - rate: 450 $\mathrm{mL} \cdot \mathrm{min}^{-1}, \Delta t=2.5 \mathrm{~s}$ )
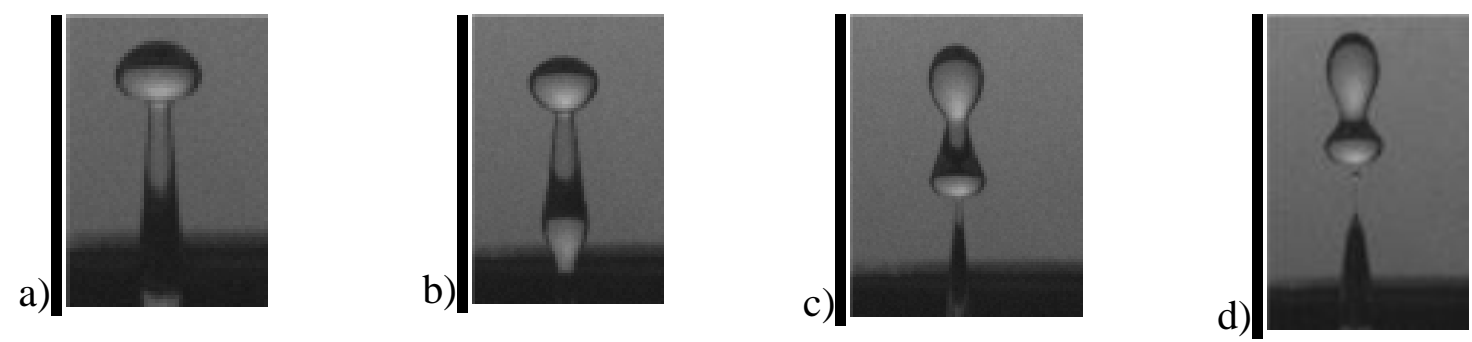

Figure 19: Formation of drops and satellite drops of DEHP (rate: $360 \mathrm{~mL} \cdot \mathrm{min}^{-1}$, $0.06 \mathrm{~s})$ 


\section{Conclusion}

In the event of a chemical spill at sea and to determine the most appropriate response strategy, it is crucial to be aware of the behavior of the substances involved. Different modes of behavior can occur after a spill: sinking, mid-water floating, dissolving, surface floating and or evaporating. As these behaviors can occur in deepwater, mid-water, surface and even atmosphere, the locations have to be known to prevent harm to responders. Moreover the final quantity in every environment and the kinetics of degradation allow the determination of the pollution type and the adequate response. Indeed the consequences will be different regarding the behavior of the chemical: for example the acidification of the water column will not have the same consequences as the formation of explosive cloud. It is also possible that chemicals may be persistent and form a concentrated organic phase, i.e. a single phase of chemical within the water column. They may become diffused on a molecular level so as to fully form a single phase i.e. an aqueous phase in which some of the chemical is dissolved. Then as water forms the main part, the situation will be less dangerous than the previous one.

The Cedre Experimental Column enables the testing of products in the water column and can be used to determine the rate at which they rise and dissolve according to parameters such as their physico-chemical properties, release rate etc. Through the tests presented in this paper, the dissolution of 5 chemicals was determined: butanol, ethanol, propanol, acetone and Methyl Ethyl Ketone. These substances, whose solubility was greater than 77,000 mg.L $\mathrm{L}^{-1}$, completely dissolved in the water column $(3 \mathrm{~m})$ at low rates $\left(200 \mathrm{~mL} \cdot \mathrm{min}^{-1}\right)$. The other products showed lower dissolution, however these trials did not allow them to be quantified.

The image sequences recorded during these tests showed that the light diffuser technique is only suitable for a small number of substances. The dissolution plumes of the 3 substances that immediately dissolved (ethanol, propanol and acetone) were barely analyzable. The other chemicals formed drops that were more (DEHP, styrene) or less (pentane, MTBE) visible to the naked eye. This visibility was related to the refractive indices of certain substances being very close to that of the water (Table 2). To improve the visibility of these products in water, future research will focus on experiments with other optical methods, such as:

- Parallel shadowscopy to observed small differences of refractive index. This method makes it possible to visualize all compounds in the water column.

- PLIF (Planar Laser-Induced Fluorescence) to study the concentrations of soluble products in the plume (Ferrier, Funk et al. 1993; Webster, Rahman et al. 2003; Crimaldi 2008). The difficulty of the PLIF lies in the choice of dye, which must be hydrophobic but miscible with the substances to be tested. However tests should be performed to ensure that dye does not affect the products solubility.

- PIV (Particle Image Velocimetry) to study plumes of droplets (Cheng, Murai et al. 2005 studied the velocity of bubbles in water).

PIV is often used together with one or other of the two other techniques or the 3 techniques may even be used together (Tokuhiro, Maekawa et al. 1998; Fujiwara, Danmoto et al. 2004; Sathe, Thaker et al. 2010). The association of these different methods can enable 2 fluids to be studied simultaneously (visualization of drops and movements around them). These experimental techniques of visualization will be developed and compared during our work with Ecole des Mines d'Alès.

Beside these experimental researches, the development of a numerical model based on flow equation but taking into account the solubility effects is under progress.

Thus in case of an accident involving a chemical tanker shipwreck, responders will have different tools available for decision-making aid. The numerical model will give information on the short term chemical behavior and on the polluted environment. Then, the development of the imaging system adapted to the CEC will enable any kind of chemical behaviors study. These experiments will 
be achieved by Cedre in brief delay to advise the authorities for an adapted safety response. Finally, data from this study (15 chemicals) and future works will complete database and provide feedback about a chemical release from depth. These will provide operators in charge of response with information on the fate of substances rising through the water column to be study in different environments and therefore their hazardous nature.

\section{Acknowledgements}

The authors are grateful to French Navy for financial support.

\section{References}

Bonn Agreement (1994). European classification system. Bonn Agreement: Counter-Pollution Manual. London.

Cedre (2006). "Accident du chimiquier Ece." Bulletin d'Information du Cedre 22: 4-9.

Cheng, W., Y. Murai, et al. (2005). "Bubble velocity measurement with a recursive cross correlation PIV technique." Flow Measurement and Instrumentation 16(1): 35-46.

Copin-Montégut, G. (2002). "Propriétés physiques de l'eau de mer." Techniques de l'ingénieur.

Cramer, C., P. Fischer, et al. (2004). "Drop formation in a co-flowing ambient fluid." Chemical Engineering Science 59(15): 3045-3058.

Crimaldi, J. (2008). "Planar laser induced fluorescence in aqueous flows." Experiments in Fluids 44(6): 851-863.

Ferrier, A. J., D. R. Funk, et al. (1993). "Application of optical techniques to the study of plumes in stratified fluids." Dynamics of Atmospheres and Oceans 20(1-2): 155-183.

Fujiwara, A., Y. Danmoto, et al. (2004). "Bubble deformation and flow structure measured by double shadow images and PIV/LIF." Experiments in Fluids 36(1): 157-165.

IMO (2006). International Convention for the Prevention of Pollution from Ships, 1973, as modified by the Protocol of 1978 relating thereto (MARPOL). London.

IMO (2007). IBC Code: International Code for the Construction and Equipment of ships Carrying Dangerous Chemicals in Bulk. 2007 Edition. London.

Lacoste, R. (2008). "Les transports de produits chimiques : un marché jeune en mutation." Note de synthèse $n^{\circ} 103$, ISEMAR.

Le Floch, S., H. Benbouzid, et al. (2009). "Operational device and procedure to test the initial dissolution rate of chemicals after ship accidents: the Cedre Experimental Column." The Open Environmental Pollution \& Toxicology Journal 1: 1-10.

Poisson, C. (2001). Comportement des substances chimiques déversées accidentellement en mer. Rapport de stage (S.2001.06). Maîtrise de Chimie Energie Environnement. Université d'Orléans. Brest, Cedre.

Rabha, S. S. and V. V. Buwa (2010). "Experimental Investigations of Rise Behavior of Monodispersed/Polydispersed Bubbly Flows in Quiescent Liquids." Industrial \& Engineering Chemistry Research 49(21): 10615-10626.

Sathe, M. J., I. H. Thaker, et al. (2010). "Advanced PIV/LIF and shadowgraphy system to visualize flow structure in two-phase bubbly flows." Chemical Engineering Science 65(8): 2431-2442.

Tokuhiro, A., M. Maekawa, et al. (1998). "Turbulent flow past a bubble and an ellipsoid using shadow-image and PIV techniques." International Journal of Multiphase Flow 24(8): 13831406.

Webster, D. R., S. Rahman, et al. (2003). "Laser-induced fluorescence measurements of a turbulent plume." Journal of Engineering Mechanics-Proceedings of the ASCE 129(10): 1130-1137.

Xie, W.-H., W.-Y. Shiu, et al. (1997). "A review of the effect of salts on the solubility of organic compounds in seawater." Marine Environmental Research 44(4): 429-444. 
Zhang, X. (1999). "Dynamics of drop formation in viscous flows." Chemical Engineering Science 54(12): 1759-1774. 